MATTHEW HODES AND DAVID GOLDBERG

\title{
The treatment of refugees: service provision reflects Britain's ambivalence
}

Britain is ambivalent towards refugees. Despite periodic xenophobic outcries in the popular press, frequently exacerbated by the actions of leading politicians (Dodd \& Scott, The Guardian, p. 10, 11 August 2001), only about a third of asylum seekers are able to remain in the UK. Even those who obtain refugee status and legal rights are marginalised and experience institutional and overt racism. On the other hand, Britain has a long tradition of receiving refugees and has always upheld the principles of asylum law. Many people have arrived as refugees and integrate and achieve success in Britain. This article discusses the nature of this ambivalence and the implications regarding responses to refugees' mental health needs.

Britain, and to an even greater extent many European community countries, require more young people for their economic development. More labour is required for industries and services, including the NHS which in recent years has been actively campaigning abroad to recruit professionals such as nurses, and for many years has and will continue to rely on immigrant doctors. Asylum seeking and refugee doctors find many obstacles to obtaining work, although there are indications that this is now changing (Adams \& Borman, 2000). Many asylum seekers and refugees have university degrees and other qualifications for skilled work (The Guardian, p. 13, 3 November 2000, Refugee doctors to help ease NHS staff crisis).

Contradictory elements are evident in the Government. On the one hand, the Asylum Act 1999 sought to disperse asylum seekers across UK and away from London, often to areas with poverty and without the appropriate services to promote refugees' welfare. Extreme racism, which may include assaults and even homicide, has occurred when refugees are moved to dispersal areas. On the other hand, the government has a strong record of social inclusion policies backed up by sometimes well-resourced services to promote welfare, and to enable people to achieve their potential economically and psychologically.

From a health perspective, concern has been expressed that this population, who have been exposed to high levels of war and privation, and ongoing adversities during migration and settlement, will have high levels of health needs. Mobility and language barriers might make accessing health services difficult (Taylor \& Gair, 1999; Kmietowicz, 2001). London's health authorities have actively tried to improve access and have developed health promotion projects for this mobile population (Morgan \& Lowdell, 1999).

The response from the psychiatric profession and mental health services has been sadly muted. From a research perspective, it is striking that in the UK there have been no adequate community, clinic or in-patient studies of refugees' mental health. This is reflected in the low level of coverage of this topic in the main British psychiatric journals. From January 1996 to August 2001 the British Journal of Psychiatry has had four publications regarding refugees (only one concerned refugees in UK) and Psychiatric Bulletin had one (the BMJ had 30 publications on this topic)

The response of some writers in the field has been ambivalent towards the need for mental health service provision, arguing that while refugees have been exposed to great adversity, services might inadvertently be stigmatising and culturally inappropriate (Summerfield, 2001). Polarisation has arisen regarding the need for refugee community support and the provision of mental health services, when these do not need to be regarded as mutually exclusive.

For many individuals even the passage of time and improved social integration will not result in spontaneous improvement in psychological symptoms and reduction in social impairment (Weine et al, 1998; Sack et al, 1999). Specialist mental health services are warranted in view of the refugees' mobility, problems in accessing mainstream services and cultural/linguistic needs (Marsella et al, 1994; Hodes, 2002). Furthermore, as a group they have high levels of psychosocial disorders, especially affective and post-traumatic stress disorders, often associated with high social impairment and other aspects of complexity such as physical illness and impairment associated with torture or privation (Marsella et al, 1994; Howard \& Hodes, 2000). Many mental health professionals in community services and sector teams lack skills and resources for dealing with these problems.

Nationally there is great diversity regarding the mental health service provision for refugees. The 
an

editorial dispersal policy has probably reduced the accessibility of primary care and mental health services for many asylum seekers and refugees. However, in London, where more than $90 \%$ of refugees have been living, there are many voluntary sector services that often involve refugees as trained counsellors. The best known institution is the Medical Foundation for the Care of Victims of Torture, in London (which provides mental health services to refugees who have been tortured; website: http:// www.torturecare.org.uk). In the NHS, some health authorities are contracting mental health trusts to provide refugee services, but these have small budgets and limited skill mix, and are not adequately linked to mainstream child and adult mental health services.

Fortunately, there are signs that the situation is changing. Greater attention is being paid to inequalities in health care, including the association with ethnic minority or refugee group membership. A number of studies regarding the mental health of refugees in community and in-patient settings are planned. The NHS and voluntary sector are developing more refugee mental health services. However, a major task will be to develop appropriately accessible and tiered services with adequate links to the range of specialist clinic-based multi-disciplinary services that are needed. The interest and involvement of psychiatrists and other mental health professionals would significantly help the provision of services. Changing national policies and international events will require the continual development of services.

\section{References}

ADAMS, K. \& BORMAN, E. (2000) Helping refugee doctors. BMJ, 320 887-888.

HODES, M. (2002) Implications for psychiatric services of chronic civilian strife or war: young refugees in the UK. Advances in Psychiatric Treatment, 8 (in press).

HOWARD, M. R. \& HODES, M. (2000) Psychopathology, adversity and service utilisation of young refugees. Journal of the American Academy of Child and Adolescent Psychiatry, 39, 368-377.

KMIETOWICZ, Z. (2001) Doctors turn away refugees, conference told. BMJ, 323,653

MARSELLA, A., BORNEMANN,T EKBLAD, S., etal (1994) Amidst Periland Pain. The Mental Health and Well-Being of theWorld's Refugees. Washington, DC: American Psychological Association.

MORGAN, D. \& LOWDELL, C. (1999)A perspective from London's health authorities. In Refugee Health in London: Key Issues for Public Health

(eds J. Aldous, M. Bardsley, R. Daniell et al). pp. 57-68. London: The Health of Londoners Project.

SACK, W., HIM, C. \& DICKASON, D. (1999) Twelve-year follow-up study of Khmer youths who suffered massive war trauma as children. Journal of the American Academy of Child and Adolescent Psychiatry, 38, 1173-1179.

SUMMERFIELD, D. (2001) Asylum seekers, refugees and mental health services in the UK. Psychiatric Bulletin 25, 161-163.

TAYLOR, G. \& GAIR, R. (1999) A review of the literature on the health of refugees and asylum seekers. In Refugee Health in London: Key Issues for Public Health (eds J. Aldous, M. Bardsley, R. Daniell et al), p. 56. London: The Health of Londoners Project.

WEINE, S. M.,VOJVODA, D., BECKER, D. F. et al (1998) PTSD symptoms in Bosnian refugees 1 year after resettlement in the United States. American Journal of Psychiatry, 155 562-564

Matthew Hodes Senior Lecturer in Child and Adolescent Psychiatry, Academic Unit of Child and Adolescent Psychiatry, Faculty of Medicine, Imperial College of Science, Technology and Medicine, Norfolk Place, London W2 1PG,

David Goldberg Consultant Adolescent Psychiatrist, Adolescent Service, South West London and St George's Mental Health NHS Trust, 32 York Road, Battersea, London SW11 3QJ 